\title{
Zeolite Encapsulated Fe-poprhyrin for Catalytic Oxidation with Iodobenzene Diacetate $\left(\mathrm{PhI}(\mathrm{OAc})_{2}\right)$
}

\author{
Gholamreza Karimipour, * Maryam Rezaei, and Davoud Ashouri
}

Department of Chemistry, Yasouj University, Yasouj. 75918-74831, Iran.

Received February 21, 2013; Accepted May 5, 2013.

\begin{abstract}
Tetrakis(3-pyridyl)porphyrinatoiron(III) chloride encapsulated on NaY Zeolite [Fe(T-3-PyP)@NaY] was synthesized as a heterogeneous "ship-in-a-bottle" type catalyst and characterized by Fourier transform infrared (FT-IR), atomic absorption (AA), diffused reflectance UV-Vis (DR UV-Vis), X-ray diffraction (XRD) and scanning electron microscopy (SEM) analysis. The catalytic activity of $\mathrm{Fe}(\mathrm{T}-3-\mathrm{PyP}) @ \mathrm{NaY}$ was examined for the epoxidation of cyclohexene by $\mathrm{PhI}(\mathrm{OAc})_{2}$ in $\mathrm{CH}_{3} \mathrm{CN} / \mathrm{H}_{2} \mathrm{O}$ (5:1) and compared to that of $\mathrm{Fe}(\mathrm{T}-$ $3-\mathrm{PyP})$ as a homogenous catalyst. We found that the heterogeneous catalyst Fe(T-3-PyP)@NaY was stable and reusable for several times, and provided a mild condition and exhibited high activity and selectivity in the oxidation of alkenes to epoxides(16-94\%). As representative examples for the use of $\mathrm{Fe}(\mathrm{T}-3-\mathrm{PyP}) @ \mathrm{NaY} / \mathrm{PhI}(\mathrm{OAc})_{2}$ in organic oxidations, oxidation of 4-nitrobenzylalcohol to 4-nitrobenzaldehyde (97\%), oxidative dehydrogenation of diethyl 4-(2,6-dichlorophenyl)2,6-dimethyl- 1,4-dihydro-3,5-pyridinedicarboxylate to the corresponding pyridine (100\%), diphenylacetic acid to benzophenone $(64 \%)$ was achieved.
\end{abstract}

Keywords: Metalloporphyrin, Zeolite, Catalyst, Encapsulation, Oxidation.

\section{Introduction}

Metalloporphyrins are a class of versatile cytochrome P-450 model catalysts which facilitate the oxidation of many organic compounds $(\mathrm{C}-\mathrm{H}$ bonds activation, epoxidation and hydroxylation) by $\mathrm{PhIO}, \mathrm{NaIO}_{4}, \mathrm{H}_{2} \mathrm{O}_{2}, \mathrm{NaOCl}, \mathrm{PhI}(\mathrm{OAc})_{2}$, etc. [1]. They are also applied in analytical chemistry, medicine and material science [2]. The first report on the metalloporphyrinmediated oxidation was given by Groves and co-worker [3] in which $\mathrm{PhIO}$ was applied for hydrocarbon oxidation in the presence of iron (III) porphyrin. We have also published some papers in this area which review the nature of the catalysts, oxidants and substrates [1c, 4].

However, a major drawback is the oxidative demolition of porphyrins during their catalytic function, which results in enormously diminishing the oxidation yield. To overcome this imperfection, supporting of metalloporphyrins on an insoluble support has been extensively attempted and many papers have been published on this subject in the last decade [5]. Generally, the immobilization of metalloporphyrins offers several particular advantages over soluble catalysts, such as facilitation of catalyst separation from the reaction mixture, simplification of procedures for catalyst recycling, the possibility of adaption of the immobilized catalyst for a continuous flow process, and obtaining the desired high-yield products.

In the recent years, attention has been focused on zeolites as appropriate supports for encapsulation of metalloporphyrins, due
Resumen. Se sintetizó el catalizador cloruro de meso-Tetrakis(3-p yridyl)porphyrinatohierro(III) encapsulado en zeolita $\mathrm{NaY}$ [Fe(T-3PyP)@NaY] mediante la técnica "barco en la botella" y se caracterizó por infrarrojo con transformada de Fourier (FT-IR), absorción atómica (AA), UV-vis con reflectancia difusa (DR UV-Vis), difracción de rayos $\mathrm{X}$ (XRD) y microscopia electrónica de barrido (SEM). La actividad catalítica de $\mathrm{Fe}(\mathrm{T}-3-\mathrm{PyP}) \mathrm{NaY}$ se examinó mediante la opoxidación de ciclohexeno por $\mathrm{PhI}(\mathrm{OAc})_{2}$ en $\mathrm{CH}_{3} \mathrm{CN} / \mathrm{H}_{2} \mathrm{O}(5: 1)$ y se comparó con la de $\mathrm{Fe}(\mathrm{T}-3-\mathrm{PyP})$ como catalizador homogéneo. Encontramos que el catalizador heterogéneo $\mathrm{Fe}(\mathrm{T}-3-\mathrm{PyP}) @ \mathrm{NaY}$ fue estable y reusable en varias ocasiones, permitiendo condiciones suaves de reacción además de exhibir actividad elevada y buena selectividad en la oxidación de alquenos a epóxidos (16-94\%). Citamos como ejemplos representativos del uso de $\mathrm{Fe}(\mathrm{T}-3-\mathrm{PyP}) @ \mathrm{NaY} / \mathrm{PhI}(\mathrm{OAc})_{2}$ para las reacciones de oxidación la transformación de 4-nitrobencilalcohol a 4-nitrobenzaldehido ( $97 \%$ ), la deshidrogenación oxidativa de dietil 4-(2,6-diclorofenil)-2,6-dimetil-1,4-dihidro-3,5-piridindicarboxilato a la piridina correspondiente $(100 \%)$ y la obtención de benzofenona a partir de ácido difenilacético (64\%).

Palabras clave: Metaloporfirina, zeolita, catalizador, encapsulación, oxidación.

to their molecular-size channels and pores in three-dimensional network of well defined crystalline structures, conferring shape and size selectivity [6]. In general, the aperture size of zeolite pores ranges from 3 to $8 \AA$, and the inner diameter of interior spaces from 5 to $13 \AA$ [7]. Moreover, zeolites are neutral solids

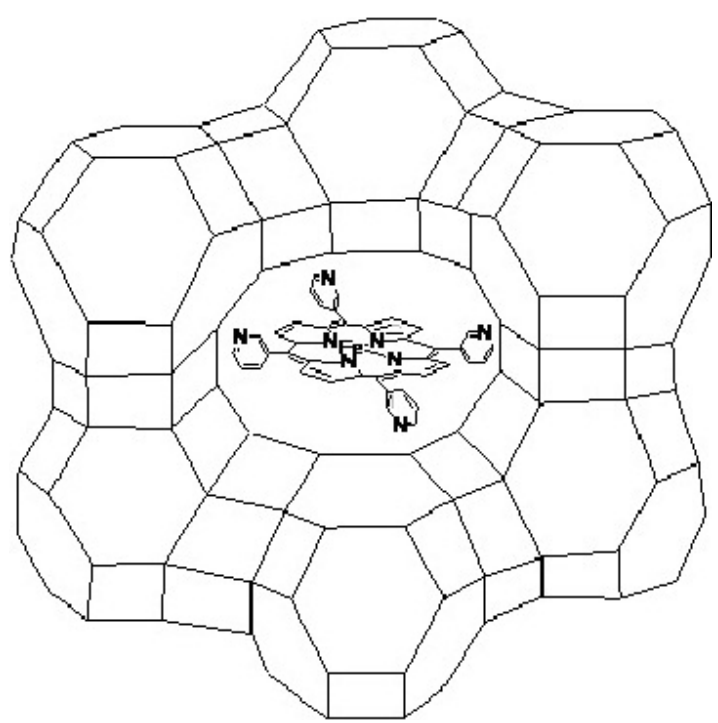

Fig. 1. [meso-Tetrakis(3-pyridyl)porphyrinato] iron(III) chloride encapsulated on NaY Zeolite [Fe(T-3-PyP)@NaY] was synthesized and characterized as a heterogeneous "ship-in-a-bottle" type catalyst. 
and could be used in organic solvents without any serious implementation problems.

In general, immobilization methods include physical entrapment, covalent binding and surface adsorption [8]. In this work, we prepared a heterogeneous oxidation catalyst through encapsulation of [meso-tetrakis(3-pyridyl) porphyrinato]iron(III) chloride complex into $\mathrm{NaY}$ zeolite (Fig. 1). This complexes (abbreviated as Fe(T-3-PyP)@NaY) is synthesized in the supercage of the zeolite just like building a ship in a bottle; such conformations are often referred to as "ship-in-a-bottle" type catalysts. The heterogeneous catalyst exhibits enhanced stability and a high turnover number, as well as good catalytic activity and selectivity in the epoxidation of alkenes by iodobenzene diacetate $\left(\mathrm{PhI}(\mathrm{OAc})_{2}\right)$ in organic media.

\section{Results and discussions}

The iron content of parent $\mathrm{NaY}$ zeolite, and Fe(T-3-PyP)@NaY catalyst was measured by dissolving a known amount of the materials in conc. $\mathrm{HNO}_{3} / \mathrm{HCl}(1: 4 \mathrm{v} / \mathrm{v})$, from these solutions the iron contents were estimated using atomic absorption spectrometer (AAS). The iron content of $\mathrm{NaY}$ zeolite, and $\mathrm{Fe}(\mathrm{T}-3-\mathrm{PyP}) @ \mathrm{NaY}$ (mmol of iron in gram of zeolite) is equal to $\sim 0.015 \mathrm{mmol} / \mathrm{g}$ and $\sim 0.36 \mathrm{mmol} / \mathrm{g}$, respectively. Therefore, the iron content of Fe(T-3-PyP)@NaY was found to be of 24 fold of the neat $\mathrm{NaY}$ zeolite, indicating the effective exchange of $\mathrm{Na}$ with $\mathrm{Fe}$ atoms in $\mathrm{NaY}$ zeolite and successful formation of $\mathrm{Fe}(\mathrm{T}-3-\mathrm{PyP})$ in the zeolite supercages.

The FT-IR spectra of NaY zeolite, Fe(T-3-PyP) and Fe(T3-PyP)@NaY are shown in Figure 2. The infrared spectrum of neat $\mathrm{NaY}$ (a) shows major bands at 3457, 1639 and 1021 $\mathrm{cm}^{-1}$. The spectrum of $\mathrm{Fe}(\mathrm{T}-3-\mathrm{PyP})$ (c) is characterized by a moderately broad band at $3417 \mathrm{~cm}^{-1}$ and some weak bands at $1027-1633 \mathrm{~cm}^{-1}$. Upon encapsulation of $\mathrm{Fe}(\mathrm{T}-3-\mathrm{PyP})$, the bands at 3457 and $1639 \mathrm{~cm}^{-1}$ shifted towards lower frequency

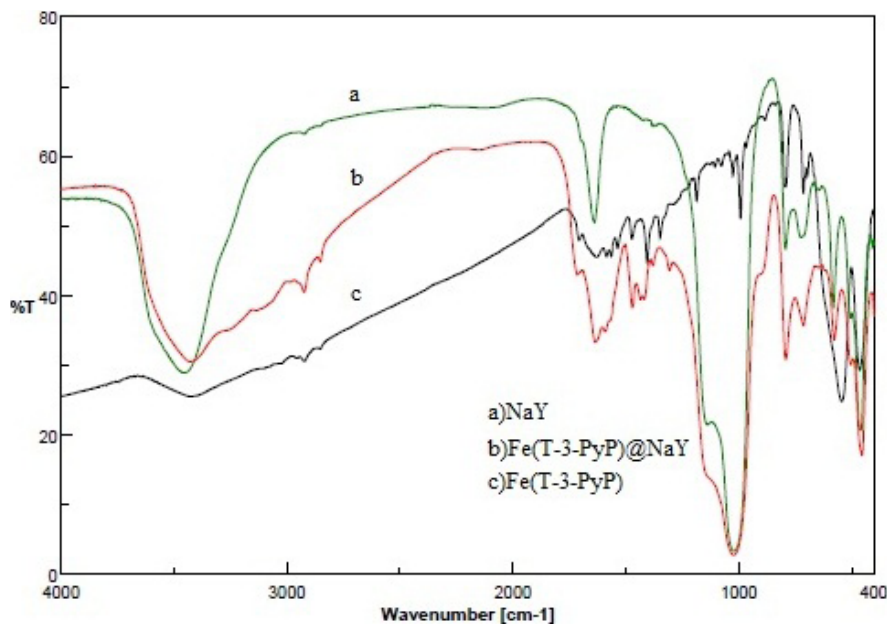

Fig. 2. FT-IR spectra of a) NaY zeolite, Fe(T-3-Py)@NaY and c) $\mathrm{Fe}(\mathrm{T}-3-\mathrm{PyP})$. at 3430 and $1635 \mathrm{~cm}^{-1}$ correspondingly, which may be due to the interaction of the metal complex with the zeolite matrix (Figure 2, b). Moreover, some weak bands of Fe(T-3-PyP) at $1027-1633 \mathrm{~cm}^{-1}$ (which may be due to the meso-pyridyl groups) appear again in the Fe(T-3-PyP)@NaY spectrum. While some bands of $\mathrm{Fe}(\mathrm{T}-3-\mathrm{PyP})$ at $500-1000 \mathrm{~cm}^{-1}$ are detectable in the Fe(T-3-PyP)@NaY spectrum, the infrared spectrum of the encapsulated metalloporphyrin demonstrates no intense bands characteristic of $\mathrm{Fe}(\mathrm{T}-3-\mathrm{PyP})$. This is the result of the low level of encapsulated Fe-porphyrin load, which guarantees its homogeneous distribution within zeolite cages.

Comparison of UV-Vis spectrum of Fe(T-3-PyP) complex (Fig. 7a, vide infra) and diffused reflectance UV-Vis of Fe(T3-PyP) encapsulated in zeolite Y (Fig. 3), confirmed the incorporation of metallopophyrin into the supercages of the

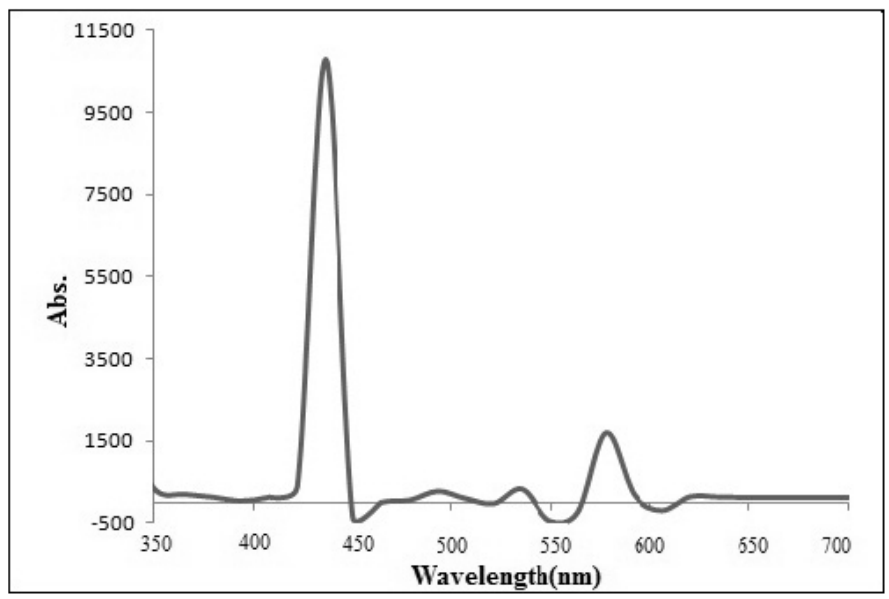

Fig. 3. Diffused reflectance UV-Vis spectra of Fe(T-3-PyP)@NaY.

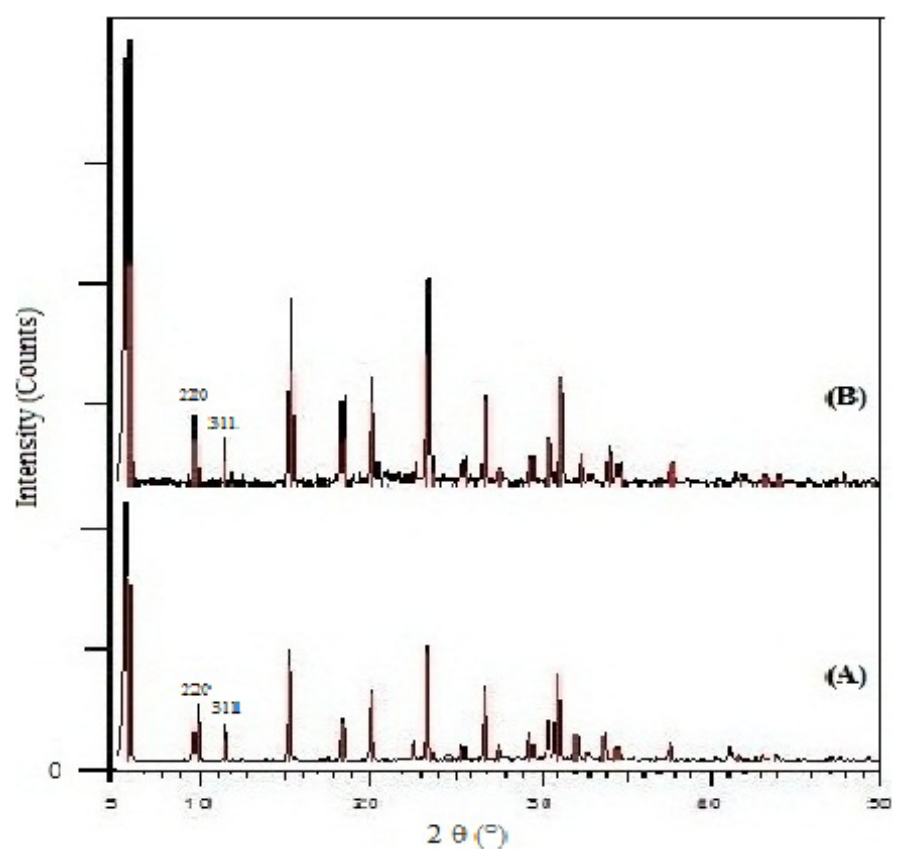

Fig. 4. XRD pattern of Fe(T-3-PyP)@NaY (a)and NaY-zeolite (b). 
zeolite. The same band is present in the UV-Vis spectra of $\mathrm{Fe}(\mathrm{T}-3-\mathrm{PyP})$ entrapped in the NaY Zeolite but the maxima have been shifted to higher wavelength and indicate that the immobilization of the complex modifies the electronic and spectral properties of the encapsulated metalloporphyrin.

The neat $\mathrm{NaY}$ zeolite and $\mathrm{Fe}(\mathrm{T}-3-\mathrm{PyP}) @ \mathrm{NaY}$ were analyzed through powder X-ray diffraction (Fig. 4). The change observed in the relative intensities of the 311 and 220 reflections upon introducing $\mathrm{Fe}(\mathrm{T}-3-\mathrm{PyP})$ result from the reported case [9] where the exchange of large cations in $\mathrm{NaY}$ Zeolite leads to disturbances in the random distribution of small extra framework cations. The change in the location of small cations affects the relative intensities of 311 and 220 peaks. Accordingly, the main framework of the zeolite is not damaged and no variation was observed in the zeolite lattice parameters after the exchange and encapsulation procedures.

Figure 5, represents the SEM image of NaY-zeolite, Fe@ $\mathrm{NaY}$ and Fe(T-3-PyP)@NaY. As it can be seen, these images are similar; indicating that they possess the same morphology, i.e., the framework around the guest molecule Fe(T-3-PyP) was faujasite-Y. These SEM images are very similar to those obtained by other researchers [10]. In general, the SEM image and XRD pattern of $\mathrm{Fe}(\mathrm{T}-3-\mathrm{PyP}) \mathrm{NaY}$ are similar to those observed for $\mathrm{NaY}$ zeolite, indicating that they possess the same morphology and crystalline structures, and that the solid supports were structurally unchanged upon encapsulation.

\section{Catalytic oxidation reactions}

In general, metalloporphyrins are expensive in view of their synthesis and purification. Moreover, they can be damaged due to degradation of their structure in the reaction mixture. Therefore, encapsulation of metalloporphyrins into natural or industrial supports prevents degradation of the catalysts and enhances their activities and turnover frequencies. In the present study, encapsulation of $\mathrm{Fe}(\mathrm{T}-3-\mathrm{PyP})$ was achieved by a $\mathrm{Na} / \mathrm{Fe}$ exchange template procedure followed by template interaction of pyrrole and pyridine-3-carboxaldehyde named as ship-in-abottle method. Fe(T-3-PyP) was also prepared as a homogenous catalyst to compare its catalytic activity with Fe(T-3-PyP)@ $\mathrm{NaY}$ as a heterogeneous catalyst. The first approach was to attain the optimized condition for epoxidation of alkenes by Fe(T-3-PyP)@NaY (Scheme 1, vide infra). The Fe(T-3-PyP) loading was quantified through measurement of the Fe content in the catalyst by $\mathrm{HNO}_{3} / \mathrm{HCl}$ digestion of $\mathrm{Fe}(\mathrm{T}-3-\mathrm{PyP}) @ \mathrm{NaY}$. The atomic absorption data show that the amount of Fe(T-3PyP) loaded on $\mathrm{NaY}$ zeolite was $2 \%$. Consequently, all the
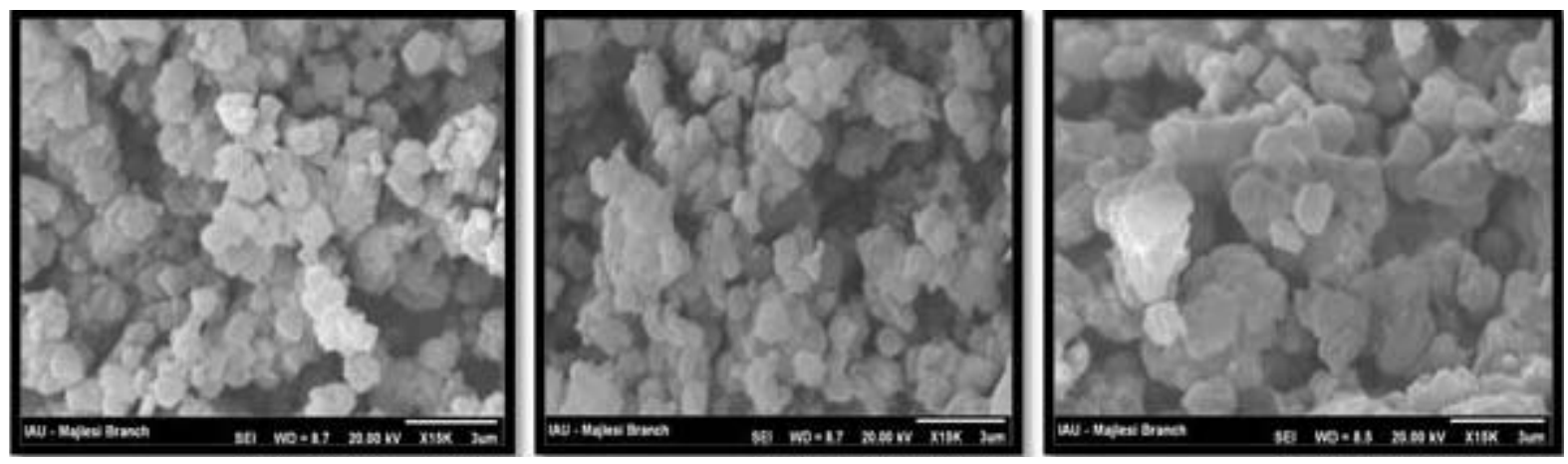

Fig. 5. SEM image of NaY-zeolite(a), Fe@NaY(b) and Fe(T-3-PyP)@NaY(c).

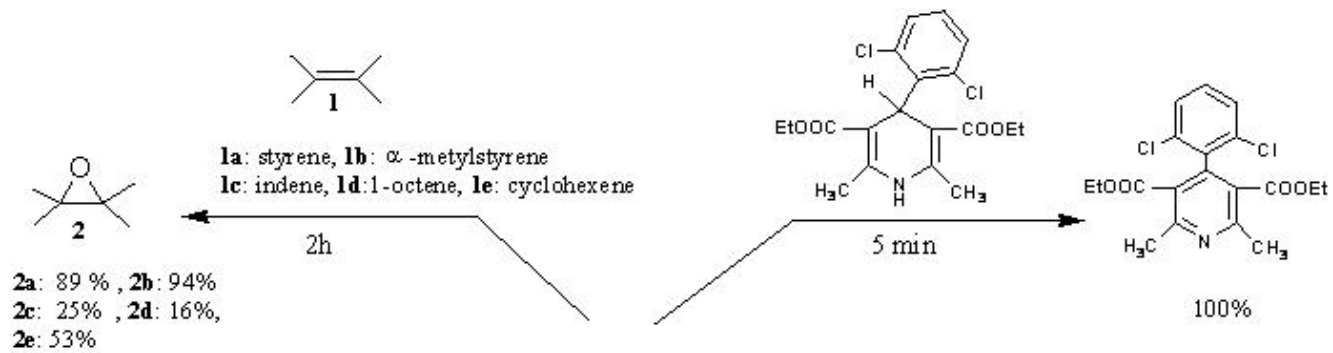

$\mathrm{Fe}(\mathrm{T}-3-\mathrm{PyP}) @ \mathrm{NaY} / \mathrm{PhI}(\mathrm{OAc})_{2}$
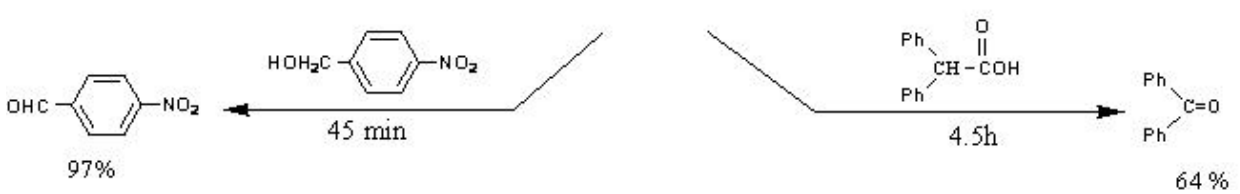

Scheme 1 Catalytic activity of $\mathrm{Fe}(\mathrm{T}-3-\mathrm{PyP}) @ \mathrm{NaY} / \mathrm{PhI}(\mathrm{OAc})_{2}$ towards organic substrates (all reactions were carried out at room temperature in $\mathrm{MeCN} / \mathrm{H}_{2} \mathrm{O}, 5: 1$ ). 
oxidations under study were achieved by $25 \mathrm{mg}$ of $\mathrm{Fe}(\mathrm{T}-3-$ PyP)@NaY which contains $8.9 \times 10^{-3} \mathrm{mmol}$ of Fe(T-3-PyP). To choose the best reaction medium, dichloromethane, ethanol and acetonitrile were applied and sodium meta-periodate $\left(\mathrm{NaIO}_{4}\right)$, peracetic acid (PAA), m-chloroperoxy benzoic acid (m-CPBA), tetrabutylammonium hydrogen monopersulfate $\left(\mathrm{OXONE}{ }^{\circledR}\right), \mathrm{H}_{2} \mathrm{O}_{2}$, and iodobenzene diacetate $\left(\mathrm{PhI}(\mathrm{OAc})_{2}\right)$ were employed as oxidants for epoxidation of cyclohexene. We found that the yield was negligible $(<4 \%)$ in the absence of the catalyst and no reaction occurred without any oxidant. Moreover, the yield is less than $5 \%$ in the presence of $\mathrm{Fe}(\mathrm{T}$ 3-PyP) as homogenous catalyst and $\mathrm{NaIO}_{4}$, PAA, m-CPBA, OXONE ${ }^{\circledR}$ and $\mathrm{H}_{2} \mathrm{O}_{2}$ oxidants. As shown in Figure 6, $\mathrm{NaIO}_{4}$, PAA, m-CPBA, OXONE and $\mathrm{H}_{2} \mathrm{O}_{2}$ have very little capability to oxidize cyclohexene into cyclohexene epoxide in $\mathrm{CH}_{2} \mathrm{Cl}_{2}$, EtOH and $\mathrm{CH}_{3} \mathrm{CN}$ in the presence of $\mathrm{Fe}(\mathrm{T}-3-\mathrm{PyP}) @ \mathrm{NaY}$. The function of the solvent may depend upon the donor number and dielectric constant which affect the stability of oxo-intermadiate participating in the metalloporphyrin-mediated oxidations [11].

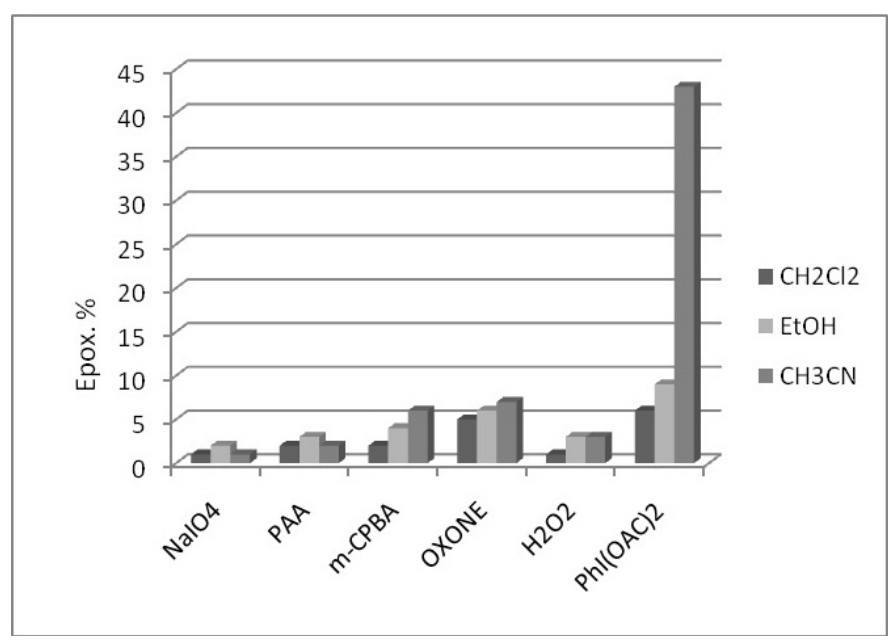

Fig. 6. Epoxidation of cyclohexene with different oxidants in various solvents.
On the other hand, the low yield and low selectivity observed for cyclohexene epoxidation in EtOH may be due to the failure associated with EtOH which can act as a substrate and compete with cyclohexene to make unwanted by-products. However, the catalyst reveals its true role in $\mathrm{CH}_{3} \mathrm{CN}$ and oxidize cyclohexene with yields as high as $53 \%$ by $\mathrm{PhI}(\mathrm{OAc})_{2}$. Therefore, the activity of the catalyst in $\mathrm{CH}_{3} \mathrm{CN}$ is higher than those in $\mathrm{EtOH}$ and $\mathrm{CH}_{2} \mathrm{Cl}_{2}$, and it is particularly preferred. It is reasonable that in situ generated $\mathrm{PhIO}$ reagent from the reaction of $\mathrm{PhI}(\mathrm{OAc})_{2}$ with water is the efficient oxygen source for the epoxidation (Eq.1) [12].

$$
\mathrm{PhI}(\mathrm{OAc})_{2}+\mathrm{H}_{2} \mathrm{O} \mathrm{PhIO}+2 \mathrm{H}_{2} \mathrm{O}
$$

Taking into account the high yield and selectivity, the epoxidation is performed in $\mathrm{CH}_{3} \mathrm{CN}$ and water using $\mathrm{Fe}(\mathrm{T}$ 3-PyP $) @ \mathrm{NaY}$ and $\mathrm{PhI}(\mathrm{OAc})_{2}$ for $2 \mathrm{~h}$ at room temperature. As defined above and in the experimental section, $25 \mathrm{mg}$ of Fe(T-3-PyP)@NaY was taken to achieve the oxidation reaction and the optimal molar ratio of Fe(T-3-PyP)@NaY, alkene and oxidant was 1:100:20.

Figure 7 shows the electronic absorption spectra at the end of the reaction (gray line; $b$ ) in comparison with $\mathrm{Fe}(\mathrm{T}$ 3-PyP) itself (black line; $a$ ). Absence of the Soret band characteristic of $\mathrm{Fe}(\mathrm{T}-3-\mathrm{PyP})$ in the mixture at the end of the reaction (spectrum $b$ ), indicates that no significant leaching of Fe-porphyrin into the reaction solution occurred during the oxidation.

In the second approach, $\mathrm{Fe}(\mathrm{T}-3-\mathrm{PyP}) @ \mathrm{NaY}$ was easily recovered by phase separation and reused under the same reaction conditions. As shown in Figure 8, the yield of cyclohexene epoxide was still $41 \%$ after four reaction cycles, indicating the reusability and validity of Fe(T-3-PyP)@NaY for alkene epoxidation.

The optimal epoxidation conditions employed for cyclohexene were also applied for epoxidation of some other alkenes. It is plausible that the steric and electronic properties of alkene substrates affect the epoxide yields and reaction times.

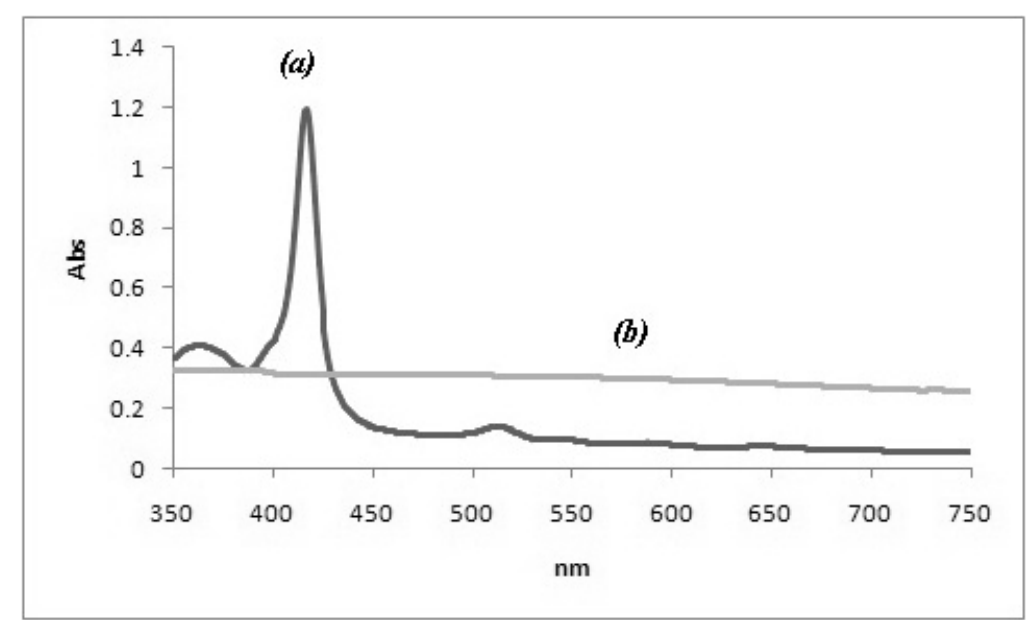

Fig. 7. Electronic absorption spectra of $\mathrm{Fe}(\mathrm{T}-3-\mathrm{PyP})$ in $\mathrm{CH}_{2} \mathrm{Cl}_{2}(a)$ and of taken from the mixture at the end of the reaction (b). 


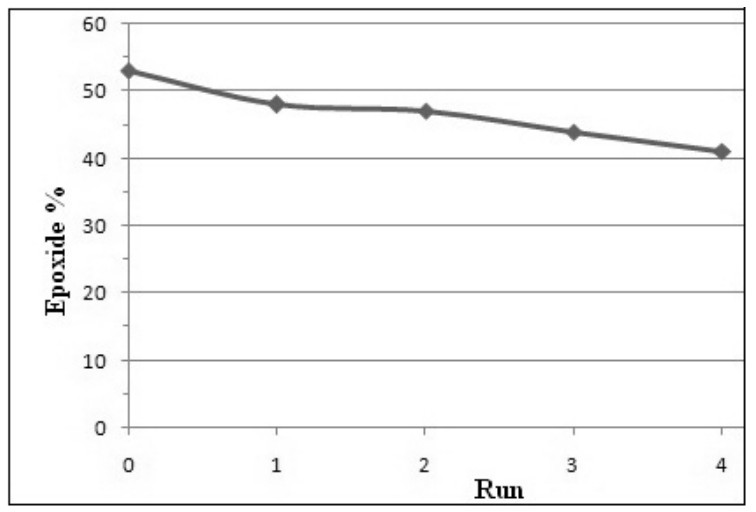

Fig. 8. Reusability of $\mathrm{Fe}(\mathrm{T}-3-\mathrm{PyP}) @ \mathrm{NaY}$ in cyclohexene epoxidation.

As shown in Scheme 1, the reactions were found to take place in $16-94 \%$ epoxide yields after stirring at room temperature for $2 \mathrm{~h}$. Exceptionally, styrene (1a) converts into $89 \%$ of styrene epoxide (2a) and $7 \%$ of an unknown byproduct; providing a selectivity of $92 \%$. Surprisingly, indene (1c) and 1-octene (1d) exhibit a lower activity for epoxidation through this catalytic system, affording indene oxide (2c) and 1-octene oxide (2d) in $25 \%$ and $16 \%$, respectively. Considering the Fe-porphyrin located in the supercage of the zeolite, explanation of the effect of steric and electronic properties of substrates in the product distribution is not a simple task. A comparison of cyclohexene epoxide obtained by $\mathrm{Fe}(\mathrm{T}-3-\mathrm{PyP})$ as heterogeneous catalyst with Fe(T-3-PyP)@NaY shows that i) Fe(T-3-PyP) does not show any significant catalytic improvement in total conversion $(<5 \%)$ and, ii) the turnover number (TON ; the ratio of the number of moles of produced epoxide to the number of moles of catalyst) for the later catalyst was 10.6 times higher than that of the former.

This result confirms that the encapsulation of Fe(T-3PyP) on NaY-zeolite makes it a more efficient catalyst for oxidation. To investigate the applicability of Fe(T-3-PyP)@ $\mathrm{NaY} / \mathrm{PhI}(\mathrm{OAc})_{2}$, we performed a set of other representative oxidation reactions that are typical of metalloporphyin-mediated reactions. The final products were isolated and their electronic data confirmed their identity with the known compounds. As shown in Scheme 1, oxidation of 4-nitrobenzyl alcohol with Fe(T-3-PyP)@NaY/ PhI $(\mathrm{OAc})_{2}$ affords 4-nitrobenzaldehyde in $97 \%$ without any over oxidation to 4-nitrobenzoic acid. Accordingly, $\mathrm{Fe}(\mathrm{T}-3-\mathrm{PyP}) @ \mathrm{NaY} / \mathrm{PhI}(\mathrm{OAc})_{2}$ provide a mild catalytic oxidation system. Although alcohol oxidation is not generally a difficult job, harsh conditions were necessary for decarboxylation of aryl acetic acids [4a, 13]. However, we can clearly see that this catalytic system promotes adequately decarboxylation of diphenylacetic acid, leading to the formation of benzophenone as a sole product in $64 \%$ yield (Scheme 1).

On the other hand, Hantzsch 1,4-dihydropyridines (1,4-DHPs) have received more attention because of their relevant applications in various cardiovascular diseases and hypertension, and their pharmacological activity in antioxidant protective effects [14]. In human body the main metabolic route of dihydropyridine drugs involve their oxidation by cytochrome-450 in the liver [15]. Likewise, oxidation of diethyl 4-(2,6-dichlorophenyl)-2,6-dimethyl- 1,4-dihydro-3,5pyridinedicarboxylate, as a sample reaction for dehydrogenation of Hantzsch-1,4-DHPs, was achieved in a few minutes by $\mathrm{Fe}(\mathrm{T}-3-\mathrm{PyP}) @ \mathrm{NaY} / \mathrm{PhI}(\mathrm{OAc})_{2}$ catalytic system with $100 \%$ selectivity and yield (Scheme 1). These results point to the catalytic stability, reusability and efficiency of $\mathrm{Fe}(\mathrm{T}$ 3-PyP $@ \mathrm{NaY}$ in combination with $\mathrm{PhI}(\mathrm{OAc})_{2}$, providing a promising catalytic system for oxidation of a wide range of materials .

Cytochrome P450 is a heme-containing enzyme that uses dioxygen to incorporate one oxygen atom into organic substrates. Clearly, the characterization of the mechanism that ensures the oxygen transfer into substrates constituents a major task for present research in the field of biomimetic chemistry. Today, it is accepted that a high-valent iron(IV)-oxo intermediate is responsible for the in-vivo oxidation of drugs and xenobiotics. This high valent iron(IV)-oxo intermediate and probably other intermediates of the P-450 catalytic cycle can be formed by the reaction of iron(III) porphyrins with different monooxygen donors [1a, 16]. Therefore, cytochrome P-450 enzymes and their synthetic mimics (i.e. metalloporphyrins) are potent catalysts that are able to catalyze the hydroxylation of saturated carbon hydrogen bonds, the epoxidation of double bonds, the oxidative dealkylation reactions of amines, oxidations of aromatics, and the oxidation of heteroatoms [1b, 17]. From the mechanistic point of view, $\mathrm{PhIO}$ was generated in situ by the reaction of $\mathrm{PhI}(\mathrm{OAc})_{2}$ with $\mathrm{H}_{2} \mathrm{O}$ (Eq.1; vide supra). It is thus inevitable that the high valent $\mathrm{Fe}$-oxo porphyrin will be produced in the second stage by the action of PhIO and the immobilized Fe(T-3PyP), as described by Groves and others $[3,18]$. In the reaction

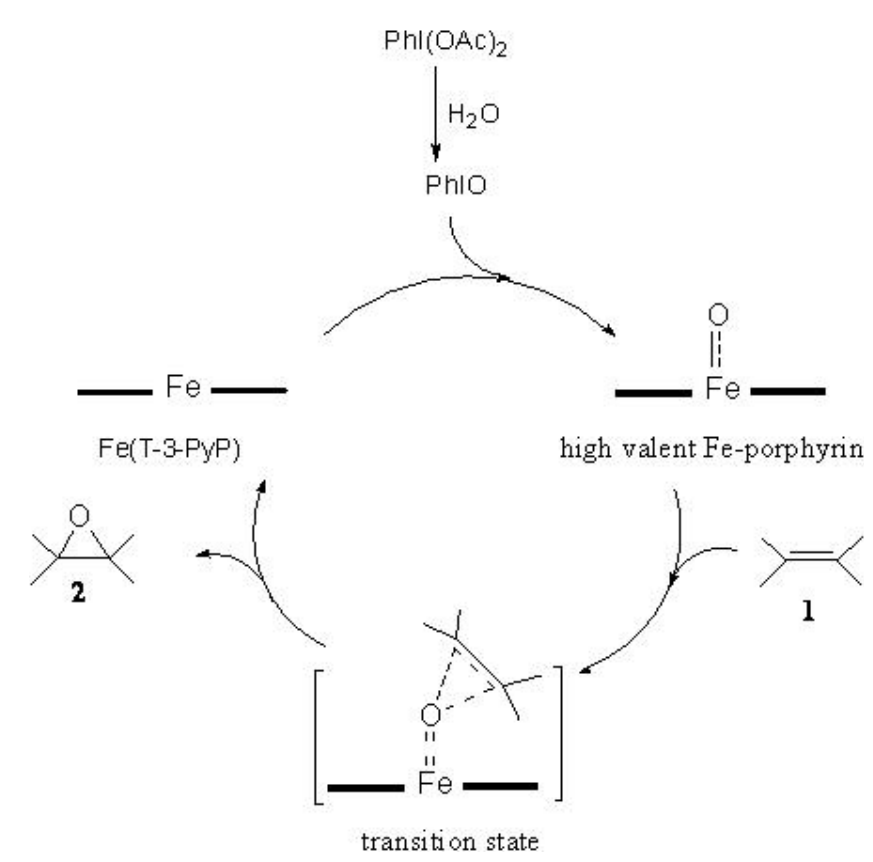

Scheme 2 Simple catalytic cycle for alkene epoxidation by Fe(T-3$\mathrm{PyP} @ \mathrm{NaY} / \mathrm{PhI}(\mathrm{OAc})_{2}$. 
mixture interaction of the high valent $\mathrm{Fe}$-oxo porhyrin with substrates (i.e alkene 1) passes through a transition state and results in oxidation of the substrates to give the corresponding oxidation products (i.e. epoxides 2) (Scheme 2).

In the present study, meso-tetrakis(3-pyridyl)porphyrina toiron(III) chloride complex; Fe(T-3-PyP), was immobilized in NaY-zeolite using template ship-in-a-bottle method and the synthesized sample (Fe(T-3-PyP)@NaY) was characterized by various spectroscopic techniques. Both the $\mathrm{Fe}(\mathrm{T}-3-\mathrm{PyP})$ and Fe(T-3-PyP)@NaY) as homogenous and heterogeneous catalysts respectively, were used for alkene epoxidation with $\mathrm{PhI}(\mathrm{OAc})_{2}$ in the presence of water. The results show that Fe(T-3-PyP)@NaY catalyst is more efficient than Fe(T-3PyP), because of (i) catalyst recovery and reusability, (ii) lower level of leaching from the support (iii) mild conditions with easy workup of the products and (iv) high turnover number. The present catalytic system is efficient enough to oxidize various alkenes, alcohols, arylacetic acids and Hantzsch 1,4dihydropyridines with high to excellent yield and selectivity.

\section{Experimental}

\section{Materials}

All reagents were of commercial reagent grade and used without further purification. $\mathrm{FeCl}_{2} \cdot 4 \mathrm{H}_{2} \mathrm{O}$ (Sigma) was employed for zeolite ion exchange. Methanol, ethyl acetate, n-hexane, dichloromethane and acetonitrile were treated and distilled with specific reference to the procedures described in the relevant literature [19]. Propionic acid and pyrrole (Aldrich) were used freshly distilled. All solvents were stored over activated 3 or $4 \AA$ molecular sieves (Aldrich). The $\mathrm{NaY}$ zeolite was purchased from Sigma Aldrich. Powder X-ray diffraction (XRD) measurements were performed using Bruker D8 Advance diffractometer with a scanning range of $2 \theta$ scale of $5-80^{\circ}$ using $\mathrm{Cu} / \mathrm{K}$-radiation $(\lambda$ $=1.5406 \mathrm{~A}^{\circ}, \mathrm{kV}=40, \mathrm{~mA}=40$ ). Atomic absorption spectra (AAS) were recorded on a Varian-240 spectrophotometer using a flame approach, after acid $\left(\mathrm{HNO}_{3} / \mathrm{HCl}\right)$ dissolution of known amounts of the zeolitic materials. Diffuse Reflectance UV-Visible spectra (DR UV-Vis) were recorded by an Ava Spec-2048TEC spectrometer (Light Source: AvaLight DH-S (Just for DRS spectrum). UV-vis spectra were recorded on a Jasco V-530 spectrophotometer and the FT-IR spectra were evidenced in the range of $400-4000 \mathrm{~cm}^{-1}$ using a Jasco FT-IR460 plus spectrophotometer, in $\mathrm{KBr}$ pellets containing zeolitic compounds or free metalloporphyrins. The micrographs from scanning electron microscopy (SEM) were obtained using a Philips XL-30 microscope equipped with an EDS system. The products were initially identified by a comparison with authentic specimens and analyzed by GLC(6890N Agilent; 1.5 $\mathrm{m}$ of $10 \%$ SE-on packed column, FTIR and ${ }^{1} \mathrm{H}$ NMR (250 $\mathrm{MHz}$, Bruker, CDCl3, TMS) spectroscopy.

Preparation of 5,10,15,20-tetra (3-pyridyl) porphyrin (T-3-PyP) and iron 5,10,15,20-tetra (3-pyridyl) porphyrin [Fe(T-3-PyP)].
T-3-PyP was prepared according to the procedure described by Zilio via condensation of freshly distilled pyrrole with pyridine-3-carboxaldehyde [20]. The iron porphyrin $\mathrm{Fe}(\mathrm{T}$ 3 -PyP) was prepared in refluxing dimethylformamide in the presence of ferrous chloride according to the procedure of Adler [21]. The porphyrin and its iron complex were purified by column chromatography on alumina or silica gel using chloroform/ ethanol $(1: 3 \mathrm{v} / \mathrm{v})$ as eluent.

\section{Preparation of $\mathrm{Fe} @ \mathrm{NaY}$}

The Fe-exchanged $\mathrm{NaY}$ zeolite (Fe@ $\mathrm{NaY})$ is air sensitive and its synthesis requires air-free techniques. So, the exchange procedure was carried out under nitrogen atmosphere using deionized, boiled and degassed distilled water. In a three neck vessel installed inside a glove bag, $8.0 \mathrm{~g}$ of $\mathrm{NaY}$ zeolite was left under nitrogen stream, stirred with $300 \mathrm{~mL}$ of $\mathrm{H}_{2} \mathrm{O}$ and $0.15 \mathrm{ml}$ drops of concentrated $\mathrm{HCl}$ for $2 \mathrm{~h}$ [22]. The $\mathrm{Fe}(\mathrm{II})$ solution was prepared using $1.6 \mathrm{~g}$ of $\mathrm{FeCl}_{2} \cdot 4 \mathrm{H}_{2} \mathrm{O}$ with 160 $\mathrm{mL}$ of degassed $\mathrm{H}_{2} \mathrm{O}$ and treated with $0.1 \mathrm{ml}$ of concentrated $\mathrm{HCl}$. This solution was then added to the NaY system and the mixture was stirred for $12 \mathrm{~h}$ always under dynamic nitrogen atmosphere. The mixture was filtered, washed and the solid was transferred to a degassed tube and dried in an Abderhalden apparatus. The color of the solid changed from white-green to light yellow in the regular atmosphere during 5-10 h. So, it should be kept under nitrogen or argon in tightly closed vessels to prevent oxidation of the absorbed $\mathrm{Fe}$ (II) ions.

\section{Preparation of Fe(T-3-PyP)@NaY}

A suspension of $2.0 \mathrm{~g}$ of fresh $\mathrm{Fe} @ \mathrm{NaY}, 60 \mathrm{~mL}$ of propionic acid, $1.0 \mathrm{~mL}$ of freshly distilled pyrrole and $1.50 \mathrm{~mL}$ of pyridine3-carboxaldehyde were placed in round-bottomed three neck flask fitted with septum, reflux condenser and nitrogen inlet port. The mixture was stirred under a nitrogen atmosphere, in a glycerin bath at $135-140{ }^{\circ} \mathrm{C}$, for $24 \mathrm{~h}$. The suspension was centrifuged and the solid obtained was washed by a Soxhlet extraction in dichloromethane and methanol (duration of 100 $\mathrm{h}$ or more) until the eluent was colorless.

\section{Catalytic oxidation reaction}

Catalytic oxidation reactions were carried out in a $2 \mathrm{ml}$ round bottom flask equipped with a magnetic stirrer at room temperature. In a standard experiment within the reactor, alkene $(0.89 \mathrm{mmol})$ and $\mathrm{Fe}(\mathrm{T}-3-\mathrm{PyP}) @ \mathrm{NaY}\left(25 \mathrm{mg}\right.$, containing $8.9 \times 10^{-3} \mathrm{mmol}$ of $\mathrm{Fe}(\mathrm{T}-3-\mathrm{PyP})$ were suspended in $1.25 \mathrm{ml}$ of acetonitrile containing $0.25 \mathrm{ml}$ of water. The oxidant $\left(\mathrm{PhI}(\mathrm{OAc})_{2} ; 0.057\right.$ $\mathrm{g} ; 0.178 \mathrm{mmol}$ ) was then added and the oxidation reaction was carried out under magnetic stirring for the required time. Small aliquots of the reaction mixture were then separated from the zeolitic solid and the resulting solution was directly analyzed by GLC (Agilent $6890 \mathrm{~N}$, with SE-30 capillary column). No products were detected when the catalyst used was NaYzeolite or $\mathrm{Fe} @ \mathrm{NaY}$. Similar reaction conditions were also applied 
for the alcohol, arylacetic acid and 1,4-dihydropyridin (1,4DHP) oxidations to evaluate the oxidation capability of the catalyst.

\section{Acknowledgements}

The financial support of this study by Yasouj University Research Council is acknowledged.

\section{References}

1. a) Meunier, B.; de Visser, S. P.; Shaik, S. Chem. Rev. 2004, 104, 3947-3980; b) Meunier. B. Chem. Rev. 1992, 92, 1411-1456; (c) Mohajer, D.; Karimipour, G.; Bagherzadeh, M. New. J. Chem. 2004, 28, 740-747.

2. a) Feese, E.; Sadeghifar, H.; Graze, H. S.; Argyropoulos, D. S.; Ghiladi. R. A. Biomolecules, 2011, 12, 3528-3539; b) Biesaga, M.; Pyrzynska, K.; Trojanowicz, M. Talanta. 2000, 51, 209-224.; c) Suslick, K. S.; Rakow, N. A.; Kosal, M. E.; Chou, J-H. J. Porphyrins Phthalocyanines 2000, 4, 407-413.

3. Groves, J. T.; Nemo, T. E.; Myers, R. S. J. Am. Chem. Soc. 1979, 101, 1032-1033.

4. a) Karimipour, G.; Karami, B.; Montazerozohori, M.; Zakavi, S. Chin. J. Catal. 2007, 28, 940-946.; b) Karimipour, G.; Montazerozohori, M.; Karami. B. J. Chem. Res. 2006, 605-608.

5. a) Viana, I. L.; Manso, C. M. C. P.; Serra, O. A.; Iamamoto, Y. J. Mol. Catal. A. 2000, 160, 199-208.; b) Benedito, F. L.; Nakagaki, S.; Saczk, A. A.; Peralta-Zamora, P. G.; Costa, M. C. M. Appl. Catal. A. 2003, 250, 1-11; c) Hibino, T.; Jones, W. J. Mater. Chem. 2001, 11, 1321-1323.; (d) Madadi, M.; Rahimi, R. Reac. Kinet. Mech. Cat. 2012, 107, 215-229.

6. a) Poltowicz, J.; Pamin, K.; Tabor, E.; Haber, J.; Adamski, A.; Sojka, Z. Appl. Catal. A. 2006, 299, 235-242.; b) Hutchings, G. J. Chem. Commun. 1999, 4, 301-306.; c) Nakagaki, S.; Xavier, C. R.; Wosniak, A. J.; Mangrich, A. S.; Wypych, F.; Cantao, M. P.; Denicolo, I.; Kubota, L. T. J. Colloid Surf. A. 2000, 168, 261-276.; d) Suib S. L. Chem Rev. 1993, 93, 803-826.

7. Yoon, K. B. Chem. Rev. 1993, 93, 321-339.

8. a) Biazzotto, J. C.; Sacco, H. C.; Ciuffi, K. J.; Neri, C. R.; Ferreira, A. G.; Iamamoto, Y.; Serra, O. A. J. Non-Cryst.Solids. 1999, 247,
134-140.; b) Iamamoto, Y.; Sacco, H. C.; Biazzotto, J. C.; Ciuffi, K. J. An. Acad. Bras. Ci. 2000, 72, 59-66.; c) Sacco, H. C.; Biazzotto, J. C.; Ciuffi, K. J.; Serra, O. A.; Nascimento, O. R.; Zuchi, M. R.; Leite, C. A. P.; Iamamoto, Y. J. Non-Cryst. Solids. 2000, $273,150-158$.

9. Ahmed, A. H.; Mostafa, A. G. Material Science and Engineering C. 2009, 29, 877-883.

10. Nakagaki, S.; Xavier, C. R.; Wosniak, A. J.; Mangrich, A. S.; Wypych, F.; Cantao, M. P.; Denicolo, I.; Kubota, L. T. Colloids and surfaces A: Physicochemical and Engineering 2000, 168, 261-276.

11. a) Takahashi, A.; Kurahashi, T.; Fujii, H. Inorg. Chem. 2011, 50, 6922-6928.; b) Drazen O., Bruice T. C. Acc. Chem. Res. 1992, 25, 314-320.

12. In. J. H.; Park, S. E.; Song, R.; Nam, W. Inorg. Chim. Acta 2003, 343, 373-376.

13. Tanner, D. D.; Osman, S. A. A. J. Org. Chem. 1987, 52, 46894693.

14. a) Oike, M.; Inoue, Y.; Kitamura, K.; Kuriyama, H. Circ. Res. 1990, 67, 993-1006.; b) Yamamoto, T.; Niwa, S.; Ohno, S.; Onishi, T.; Matsueda, H.; Koganei, H.; Uneyama, H.; Fujita, S.-i.; Takeda, T.; Kito, M.; Ono, Y.; Saitou, Y.; Takahara, A.; Iwata, S.; Shoji, M. Bioorg. Med. Chem. Lett. 2006, 16, 798-802.

15. Guengerich, F. P.; Martin, M. V.; Beaune, P. H.; Kremers, P.; Wolff, T.; Waxman, D. J. J. Biol. Chem. 1986, 261, 5051-5060.

16. (a) Tshuva, E. Y.; Lippard, S. J. Chem. Rev. 2004, 104, 987-2011.; (b) Costas, M.; Mehn, M. P.; Jensen, M. P.; Que, L., Jr. Chem. Rev. 2004, 104, 939-986.

17. (a) Meunier, B. Biomimetic Oxidations Mediated by Metal Complexes; Imperial College Press:London, 2000; b) Meunier, B. $\mathrm{Me}$ talloporphyrin Catalyzed Oxidation; Kluwer Academic Publisher, 1994.

18. Kang, M. J.; Song, W. J.; Han, A. R.; Chi, Y. S.; Jang. H. G.; Nam, W. J. Org. Chem. 2007, 72, 6301-6304.

19. Perrin, D. D.; Armarego, W. L. F.; Perrin, D. R. Purification of Laboratory Chemicals, Pergamum Press, Elmsford, NY, $2^{\text {nd }}$ ed, 1980.

20. Neto, N. M. B.; Boni, L. De.; Rodrigues, J. J.; Misoguti, L.; Mendonça, C. R.; Dinelli, L. R.; Batista, A. A.; Zilio, S. C. J. Porphyrins Phthalocyanines 2003, 7, 452-456.

21. Adler, A. D.; Longo, F. R.; Finarelli, J. D.; Goldmacher, J.; Assour. J.; Korsakoff, L. J. Org. Chem. 1967, 32, 476.

22. Pearce, J. R.; Mortire, W. J.; Uytterhoeven, J. B.; Lunsford, J. H. Faraday Trans. 1981, 177, 937. 